\title{
O CONHECIMENTO DO CONHECIMENTO: Uma Estratégia da Escola Para Ensinar a Viver
}

\author{
Celso Francisco Tondin ${ }^{1}$ \\ Sirlei Antoninha Kroth Gasparetto ${ }^{2}$ \\ Claudete Teresinha Junges ${ }^{3}$
}

\begin{abstract}
RESUMO
O presente artigo tematiza a relação entre complexidade, educação e saberes transdisciplinares, e objetiva a proposição de um ensino que considere os estudos realizados pela teoria histórico-cultural em relação à aprendizagem e ao desenvolvimento, em diálogo com a complexidade do conhecimento. Trata-se de um estudo qualitativo, de caráter teórico, que tem como fontes a produção bibliográfica de autores reconhecidos por suas investigações referentes ao foco investigado. Assim, foram destacados os conceitos aprendizagem e desenvolvimento, trabalhados por Vigotski, complexidade do conhecimento de acordo com Morin e transdisciplinaridade com base em Moraes. Evidencia-se que o desenvolvimento de um humanismo complexo nas escolas já ocorre em experiências educativas e pode ser potencializado onde houver o desenvolvimento de um trabalho pedagógico que observe a aprendizagem e o desenvolvimento dos estudantes, a natureza complexa do conhecimento e reforce a curiosidade epistemológica nos sujeitos envolvidos no processo de ensino-aprendizagem.
\end{abstract}

Palavras-chave: Conhecimento. Aprendizagem. Complexidade. Transdisciplinaridade.

\section{KNOWLEDGE OF KNOWLEDGE: A SCHOOL STRATEGY TO TEACH HOW TO LIVE}

\section{ABSTRACT}

This article thematizes the relationship between complexity, education and transdisciplinary knowledge, and aims to propose a teaching process which considers the studies carried out by historical-cultural theory, in relation to learning and development and in dialogue with the complexity of knowledge. It is a qualitative study with a theorectical character that has as references the bibliographical production of authors who are recognized for their investigations referring to the investigated focus, thus, the concepts learning and development proposed by Vygotsky were highlighted, as well as the concepts of complexity of knowledge according to Morin and transdisciplinary based on Moraes. It is evidenced that the development of a complex humanism in schools already occurs in educational experiences and can be enhanced where there is a development of a pedagogical work that observes students' learning and development, the complex nature of knowledge and the potential of epistemological curiosity in the subjects involved in the teaching-learning process.

Keywords: Knowledge. Learning. Complexity. Transdisciplinarity.

RECEBIDO EM: 29/3/2018

ACEITO EM: 22/8/2018

\footnotetext{
${ }^{1}$ Graduado em Psicologia pela Universidade do Vale do Rio dos Sinos. Mestre em Psicologia pela Universidade Federal de Minas Gerais. Doutor em Psicologia pela Pontifícia Universidade Católica do Rio Grande do Sul. Docente da Graduação e Pós-Graduação em Psicologia da Universidade Federal de São João del-Rei. Diretor da Associação Brasileira de Ensino de Psicologia. https://wwws.cnpq.br/cvlattesweb/PKG MENU.menu?f_cod=68E3E22A247A5B8A202C184F970D4564\#. Orcid: https://orcid.org/0000-0001-7640-5838. celsotondin@ufsj.edu.br

2 Doutora em Desenvolvimento Regional (Unisc). Mestre em Ciências Sociais e mestre em História (PUC SP). Especialista em Educação em Direitos Humanos (EDH - Unochapecó). Especialista em Histórica no Brasil República (PUC - SP). Graduada em Pedagogia (Unoesc - Chapecó/SC). Militante do Movimento de Mulheres Camponesas - MMC/Brasil. Professora da ACHJ da Unochapecó. Orcid: https://orcid. org/0000-0001-8533-2730. sirlei@unochapeco.edu.br

${ }^{3}$ Graduada em Pedagogia - Orientação e Administração Escolar pela Unijuí. Especialista em Educação Infantil e Ensino Fundamental pela Unoesc e especialista em Psicopedagogia Clínica e Institucional pela Unochapecó. Mestre e doutoranda em Educação nas Ciências pela Unijuí. Orientadora Educacional da Rede Municipal de Ensino de Anchieta - Anchieta/SC. http://lattes.cnpq.br/9659624156303612. Orcid: https://orcid.org/0000-0003-2262-4642.claudetejunges@yahoo.com.br
} 
A responsabilidade da educação é trabalhar o conhecimento de modo que tudo aquilo que foi produzido pela experiência histórico-social humana esteja ao alcance das pessoas, a fim de promover processos de desenvolvimento. Ao se tornarem mais humanas, espera-se que as pessoas possam desenvolver práticas sociais alicerçadas nos preceitos da ética e nos conceitos das ciências, isto é, que entendam o mundo a partir do conhecimento historicamente produzido e ajam individual e coletivamente ante os desafios propostos por seu tempo.

O presente estudo objetiva a proposição de um ensino que considere os estudos realizados pela teoria histórico-cultural em relação à aprendizagem e ao desenvolvimento, em diálogo com a complexidade do conhecimento. Para tanto, assume a abordagem qualitativa e é de caráter teórico, tendo como fontes a produção bibliográfica de autores, reconhecidos por investigações referentes ao foco investigado. Assim, foram destacados os conceitos aprendizagem e desenvolvimento, trabalhados por Vigotski, ${ }^{4}$ complexidade do conhecimento de acordo com Morin e transdisciplinaridade com base em Moraes.

Os estudos realizados por Vigotski - marco de referência na psicologia educacional - deram origem à linha de pensamento da teoria histórico-cultural. Esta teoria possibilita a compreensão acerca do desenvolvimento e da aprendizagem, ultrapassando as explicações inatista e ambientalista, ou seja, que o desenvolvimento biológico precede a aprendizagem, como postula a primeira, ou que a aprendizagem depende exclusivamente da experiência proporcionada pelo ambiente, como entende a segunda.

Até os estudos de Vigotski entendia-se que o desenvolvimento precede a aprendizagem, e que ambos se dão do individual para o social, e ainda que a aprendizagem ocorre apenas na relação do sujeito com o objeto. O referido psicólogo, buscando em Marx os princípios da dialética, passa a explicar o desenvolvimento e a aprendizagem, como expõe em A formação social da mente (VIGOTSKI, 2007) nos seguintes termos: ambos, desenvolvimento e aprendizagem, são inter-relacionados; ocorrem do social para o individual; e a aprendizagem se processa na relação do sujeito com o objeto mediada por outros sujeitos.

No intuito de trabalhar a aprendizagem de modo a alcançar um ensino de qualidade que propicie o desenvolvimento humano, encontra-se em Morin, essencialmente em suas obras Ensinar a viver: manifesto para mudar a educação (2015), O método 3: o conhecimento do conhecimento (1999) e Os sete saberes necessários à educação do futuro (2000), a compreensão do conhecimento como mais abrangente, complexo e essencialmente voltado a uma resposta mais efetiva aos problemas que temos enfrentado na contemporaneidade. As ideias deste pensador são potentes para a compreensão do conhecimento, porque este é apresentado nas dimensões da humildade e da generosidade, capaz de construir "cabeças bem-feitas", o que parece fundamental quando se sonha com uma escola do futuro, no presente, apostando-se na transdisciplinaridade.

\footnotetext{
${ }^{4}$ Encontra-se na literatura diversas formas de grafar o nome deste psicólogo. No presente texto, quando a redação é dos próprios autores, a opção é pela grafia Vigotski e, quando for citação, segue-se a grafia utilizada na referência bibliográfica consultada.
} 
Moraes $^{5}$ (2015) contribui com o propósito de pensar a escola a partir da transdisciplinaridade. No livro Transdisciplinaridade, criatividade e educação: fundamentos ontológicos e epistemológicos, a autora trabalha fundamentos do conhecimento transdisciplinar e demonstra a necessidade de transformar o pensamento a fim de promover a possibilidade de novos valores e fazer frente aos desafios do nosso tempo.

A motivação da presente reflexão é o compromisso profundo com o conhecimento e o aprender de todos e todas, que é o propósito da escola no contexto da realidade de inacessibilidade de muitos estudantes à aprendizagem, resultado das formas como organizamos as escolas e do que é trabalhado nelas. Com isso, a disposição neste texto é pensar na propositura do "conhecimento do conhecimento" (MORIN, 1999) na escola como uma estratégia para ensinar a viver, como um caminho que aponta possibilidades já presentes em muitas experiências educativas.

Inicialmente, discorre-se sobre a relação da escola com o conhecimento e as críticas às formas como ele é percebido e trabalhado por ela, com o propósito de ir além e abrir brechas no fazer pedagógico hegemônico na direção do "conhecimento do conhecimento", rumando, oxalá, para uma escola que efetue o conhecimento de forma transdisciplinar. Em seguida, trabalha-se a aprendizagem e o desenvolvimento no entrelaçamento entre o caráter sociocultural e o pensamento complexo, demonstrando que esse empreendimento produz um humanismo complexo, que promove modos mais qualificados de conceber o ensino e o papel da escola contemporânea no processo de desenvolvimento da pessoa humana. Para encerrar, ousa-se elaborar algumas narrativas de possibilidades de outras formas mais criativas de organizar o conhecimento na escola, em consonância com a dialógica e um humanismo que se pode denominar de complexo, apresentando-se uma das experiências que acontecem nessa perspectiva - a da Rede Municipal de Anchieta, em Santa Catarina (SC). ${ }^{6}$

\section{RELAÇÃO DA ESCOLA COM O CONHECIMENTO}

Olhando para a escola e observando o que nos propõe Morin (1999) em O método 3: o conhecimento do conhecimento, ressurgem questionamentos evidentes: $\mathrm{Na}$ contemporaneidade estamos cumprindo nosso papel de ensinar para os estudantes 0 que de melhor foi construído em nossa tradição? O conhecimento é o que trabalhamos na escola? Estamos respeitando a complexidade do saber?

\footnotetext{
5 Maria Cândida Moraes é professora aposentada do Programa de Pós-Graduação em Educação na Universidade Católica de Brasília. É coordenadora-adjunta da Rede Internacional de Ecologia dos Saberes (Ries) da Universidade de Barcelona.

${ }^{6}$ Segundo o sítio da Prefeitura, "O município de Anchieta está situado no Extremo Oeste Catarinense, na posição norte. Conforme dados do IBGE (2012), sua área é de 283 quilômetros quadrados, o que corresponde a 0,26\% do território do Estado de Santa Catarina. O nome do município deve-se ao trabalho dos padres Pedro Rubin e Afonso Correia, que, na época, atendiam a região e passaram pelo território anchietense realizando celebrações. Como o trabalho era semelhante ao do Padre José de Anchieta, assim passou a ser denominado o município que foi emancipado em 20 de março de 1963. Antes de ser município, o território anchietense pertenceu a Chapecó, São Miguel do Oeste e Guaraciaba. "[...] O município, que conta hoje com 6.172 habitantes (IBGE, 2012), tem como base da economia a agricultura, com destaque para o cultivo de milho, feijão, soja e fumo. Na pecuária, destaca-se a criação de suínos e gado de leite". Informação disponível em: <http://www.anchieta.sc.gov.br/cms/pagina/ver/ codMapaltem/56653>. Acesso em: 24 mar. 2018.
} 
Os estudos sobre a complexidade, em Morin (1999), são potencializadores para provocar a escola no que diz respeito aos problemas colocados ao próprio conhecimento e que estão bem visíveis nesta instituição: a divisão sujeito e objeto do conhecimento; o conhecimento científico como verdade imutável e absoluta; a separação das condições de produção do conhecimento de seu resultado; e a supervalorização do computo ${ }^{7}$ em detrimento ao cogito. ${ }^{8}$

Morin (1999) propõe um circuito dialógico entre o sujeito e o objeto do conhecimento, reconhecendo que cada um desses é importante e necessário ao conhecimento porque o sujeito vai se fazer presente no objeto enquanto o objeto do conhecimento passa a fazer parte do mundo do sujeito. Nesse sentido, o pensador afirma: "A prova da realidade objetiva do mundo ao qual pertencemos nos é fornecida pela atividade subjetiva que organiza não somente o conhecimento, mas primordialmente a vida" (MORIN, 1999, p. 232). Ou seja, não pode haver conhecimento objetivo sem envolvimento da subjetividade da pessoa que conhece.

É comum que na escola o conhecimento de qualquer área seja tratado como algo distante da vida dos sujeitos, como se fosse puramente objetivo e sem o entendimento do contexto da existência dos conceitos estudados. Por exemplo, ao trabalhar poluição são mostrados os rios distantes esquecendo de olhar que logo abaixo da escola corre um riacho e que parte do esgoto da cidade escorre para ele. Isto é, o conhecimento passa a ter um caráter "mágico" e pouco ou nada implicado com a vida das pessoas que conhecem.

Essa assepsia dos conhecimentos apresentados na escola faz com que o estudante tenha a percepção de verdades únicas e isoladas do ser que conhece, além de tomá-los como perenes, negando que toda pesquisa, que gera um conhecimento, parte do desejo e da necessidade de alguém de investigar, do olhar do pesquisador sobre o objeto pesquisado e, sendo assim:

Todo conhecimento comporta aspectos individuais, subjetivos e existenciais. Nosso apego às nossas idéias, ainda que não se reduza a este único aspecto, tem caráter passional/existencial. Como qualquer paixão, a do conhecimento pode suscitar um engajamento total do ser (MORIN, 1999, p. 150-151).

Todo conhecimento objetivo parte de um olhar sobre a realidade e não reflete a realidade diretamente; é uma tradução; a representação é mais do que um reflexo quase ótico da realidade percebida: “[...] ela é ao mesmo tempo construção e tradução,

\footnotetext{
7 De acordo com Morin (1999, p. 57), "[...] a fonte de todo o conhecimento encontra-se no cômputo do ser celular, indissociável da qualidade do ser vivo e do indivíduo-sujeito" ou, ainda, "[...] se há uma dimensão cognitiva em qualquer operação computante e se a computação está apta às atividades cognitivas mais diversas, todo conhecimento, de qualquer natureza, não pressupõe a computação, e esta não pressupõe um problema a tratar? Por isso, como o propunha Gordon Park, seria preciso conceber a compútica (computation science) não como a ciência dos computadores, mas como a ciência das computações necessárias a todo conhecimento e, acrescento, a toda organização, comportando uma dimensão cognitiva para resolver os seus problemas" (MORIN, 1999, p. 48-49).

${ }^{8} \mathrm{O}$ cogito (pensamento), proposto por Descartes (2005), trouxe a dicotomia entre sujeito e objeto, alma e corpo, espírito e matéria, pensar e fazer. Segundo Morin (2010), este, que se tornou o grande paradigma do Ocidente, se traduz no que conhecemos como pensamento disjuntivo, simplificador, unilateral, que se desenvolveu ao longo da história desembocando no que chama de "paradigma de simplificação". O "pensamento complexo", ao contrário, une, complexifica, bipolariza, contrapondo-se à simplificação.
} 
mas esta tradução construtiva pode ser concebida como a produção de um análogo cerebral/espiritual da realidade percebida" (MORIN, 1999, p. 121). Ou seja, o conhecimento é uma reconstrução; é a construção de uma nova realidade, que reflete objetivamente o que foi pesquisado.

O conhecimento tem uma provisoriedade muito grande. Sua existência, enquanto verdade, ocorre até que outra verdade seja construída. Nessa direção, Morin vai buscar em Karl Popper o princípio da falseabilidade e o limite da ciência:

[...] os formidáveis progressos do conhecimento científico foram ambivalentes do ponto de vista da consciência, suscitaram tomadas de consciência fundamentais, mas produziram também regressões de consciência e falsas consciências; tudo o que fragmenta e fecha os conhecimentos, tudo o que faz sombra ao sujeito e à própria consciência, só pode atrofiá-la (MORIN, 1999, p. 214).

Muitos conhecimentos foram renegados nas instituições de ensino. Um exemplo disso são os conhecimentos chamados tradicionais. Estes foram construídos pelas pessoas na busca de respostas para os desafios enfrentados em suas relações bem mais próximas à natureza; são também conhecimentos que, por muito tempo, foram transmitidos de geração a geração e contêm, de modo geral, uma compreensão de totalidade maior pelo modo como foram construídos.

É importante analisar aqui, também, o que está em discussão hoje, no Brasil, na proposta de "reforma" do Ensino Médio, ${ }^{9}$ que possibilita ao estudante deste nível a escolha de um itinerário formativo por meio da opção por uma das áreas do conhecimento, quais sejam: linguagens e suas tecnologias; matemática e suas tecnologias; ciências da natureza e suas tecnologias; ciências humanas e sociais aplicadas; e formação técnica e profissional. Um olhar crítico e na perspectiva da formação humana integral, no entanto, demonstra que esta "reforma" estreita a formação e vai de encontro à tentativa de trabalhar o conhecimento em sua totalidade e amplitude, pois serão privilegiadas algumas disciplinas em detrimento de outras.

A contextualização do conhecimento como algo realizado, observado pelos seres humanos na busca por respostas existenciais para os mistérios, as dificuldades e as contradições da vida, coaduna com os postulados de Morin (1999, p. 151-152), quando ele aborda uma série de aspectos que demonstra o envolvimento do sujeito e de suas paixões em relação ao conhecimento: todo conhecimento comporta aspectos individuais,

\footnotetext{
${ }^{9}$ O "Novo Ensino Médio" foi instituído pela Medida Provisória (MP) no 746/16, apresentada pela presidência da República, e que foi sancionada pelo presidente Michel Temer e publicada no Diário Oficial da União no dia 17/2/2017, por meio da Lei no 13.415/2017, que altera a Lei de Diretrizes e Bases da Educação Nacional, Lei no 9.394/96. Trata-se de uma polêmica "reforma" e que tem posição contrária de importantes entidades da Educação, como a Associação Nacional de Pesquisa e Pós-Graduação em Educação (Anped). Em defesa desta "reforma", porém, o Ministério da Educação se posiciona: "A reforma do ensino médio é uma mudança na estrutura do sistema atual do ensino médio. Trata-se de um instrumento fundamental para a melhoria da educação no país. Ao propor a flexibilização da grade curricular, o novo modelo permitirá que o estudante escolha a área de conhecimento para aprofundar seus estudos. A nova estrutura terá uma parte que será comum e obrigatória a todas as escolas (Base Nacional Comum Curricular) e outra parte flexível. Com isso, o ensino médio aproximará ainda mais a escola da realidade dos estudantes à luz das novas demandas profissionais do mercado de trabalho. E, sobretudo, permitirá que cada um siga o caminho de suas vocações e sonhos, seja para seguir os estudos no nível superior, seja para entrar no mundo do trabalho". Disponível em: http://portal.mec.gov.br/component/content/article?id=40361\#nem_01. Acesso em: 20 mar. 2018.
} 
subjetivos e existenciais, com caráter passional/existencial; o conhecimento humano não deve ser desvinculado da existência, mas também não deve acorrentar-se a ela; o ideal é o sujeito viver a paixão do conhecimento e por meio do conhecimento controlar a paixão; necessidade de autoanálise para perceber o que faz as pessoas buscarem este ou aquele conhecimento; e a paixão pelo conhecimento parte da busca infinita insaciável em que o sujeito procura sua verdade fora de si.

Observa-se que, no momento de ensinar os conceitos e as próprias narrativas sobre a realidade, é operada a separação das condições de produção do conhecimento, de tal maneira que consumimos ideias, que são transmitidas pelos meios de comunicação com aparência de objetividade, como verdades, e, no entanto, são apenas opiniões de algumas pessoas cujo interesse é hegemonizar determinadas formas de pensar. Isto é, constata-se que boa parte da sociedade não possui ferramentas conceituais de análise para perceber os valores, ideologias, manipulações, tendências, etc., veiculados nos fatos noticiados, tornando-se massa de manobra de poderes constituídos.

O pensamento está entre uma das características mais importantes da vida das pessoas, afinal elas são dotadas de consciência, portanto, da capacidade de pensar sobre as ações a serem realizadas. O exercício do "pensar sobre" deveria ocupar um espaço privilegiado na escola no sentido de possibilitar aos estudantes a reflexão sobre os acontecimentos passados, a decisão sobre o que vai ser realizado no momento atual a partir das condições dadas (ter presente) e a projeção do futuro com possibilidade de sonhar. Esse exercício do pensar deve ser algo do próprio sujeito, mas também uma atividade coletiva a fim de perceber, conhecer e refletir sobre os caminhos construídos pela humanidade.

Somos também chamados na escola a considerar a provisoriedade e analisar as possibilidades do que está por acontecer, que em pequena parte é construído por nós, mas em grande parte é determinado por muitos outros atores que fazem história junto conosco em nosso tempo ou o fizeram em outros períodos. Assim, o sujeito adotar constantemente a autopercepção de seus pensares, autoavaliação de suas ações ou a autocomputação, são ações importantes propostas por Morin (1999).

Ainda, possibilitar o acesso dos estudantes ao saber construído pela humanidade, perceber os outros modos de viver que a evolução da ciência proporcionou à humanidade e compreender a tecnologia como uma construção humana que deve ser colocada a serviço de toda a humanidade, são objetivos que pressupõem que o conhecimento existente seja muito bem trabalhado e esteja organizado nos documentos curriculares, pois

[...] o pensamento atingiu seu apogeu na e através da cogitação/computação; o cérebro torna-se não mais somente máquina supercomputante, mas também máquina de pensar; o espírito toma forma não apenas de atividade cognitiva, mas de atividade pensante e consciente (MORIN, 1999, p. 139).

Como mencionado, Morin (1999) utiliza os termos computo e cogito. Computo para se referir ao conhecer o que já existe, memorizar, guardar informações, trabalhar com as informações existentes, e cogito para o pensar, refletir, elucidando que os dois estão interligados e fazem parte do funcionamento dos seres vivos, constituindo um cir- 
cuito autogerativo. O pensador emprega os seguintes termos para explicar esse processo: "[...] a cogitação (pensamento), emergente das operações computantes da máquina cerebral, retroage sobre essas computações, utiliza-as, desenvolve-as e transforma-as formulando-se na linguagem" (p. 129).

Análises mecanicistas equiparam o conhecer ao computar. Ao contrário, é pertinente afirmar que o conhecer e o pensar devem estar interligados nos processos de ensino, porque é necessário conhecimento para um pensar qualificado e há uma instrumentalização para tal que a escola deve proporcionar. Por isso, o que preocupa são as percepções existentes nas escolas do conhecer como um acúmulo de conhecimentos sem o devido pensar sobre e pensar-se neste saber. Afinal,

A consciência é inseparável do pensamento, que é inseparável da linguagem. A consciência é a emergência do pensamento reflexivo do sujeito sobre si mesmo, sobre as suas operações, ações. Como vimos, a natureza da linguagem oferece a possibilidade reflexiva que permite a todas as operações do espírito tornarem-se objetos de consciência (MORIN, 1999, p. 136).

A linguagem permite traduzir o vivido, os sentimentos, as emoções e as paixões, e o desenvolvimento do pensamento está intrinsecamente ligado à linguagem em um elo recursivo, porque pensamos com as palavras, com a nossa linguagem, e, ao mesmo tempo em que falamos, comunicamos o que pensamos. Nossos pensamentos e palavras compõem uma relação entre o abstrato e o concreto, entre a imaginação e o que existe.

\section{OBSERVÂNCIA DA TRADIÇÃO E DA COMPLEXIDADE DO SABER NA EDUCAÇÃO PARA A VIDA}

Em relação ao conhecimento historicamente construído pela humanidade e a sua importância na educação para a vida e na educação para o ser mais, há a tarefa de apresentação da geração presente para as que chegam. Essa dimensão da tradição tem por finalidade que ninguém seja relegado à ignorância, e, por isso, é essencial que a escola reflita constantemente sobre os modos de conhecer, sobre os desejos, sobre a necessidade de conhecer presentes nas novas gerações.

Uma oportuna e necessária reflexão realizada por Hannah Arendt (2002), refere-se ao nosso compromisso com as novas gerações, à competência do educador acerca do conhecimento do que existe no mundo e à corresponsabilidade da escola com o mundo das pessoas que chegam a ela, pois "[...] a competência do professor consiste em conhecer o mundo e em ser capaz de transmitir esse conhecimento aos outros. Mas a sua autoridade funda-se em seu papel de responsável pelo mundo" (p. 10).

À medida que Arendt (2002) relembra da importância do ensino a partir da tradição, Morin (1999) trata do compromisso da escola em ensinar, fazendo uma conceituação do conhecimento como: tradução em representações, ideias e teorias; construção de sistemas cognitivos articulando informações, signos e símbolos; solução de problemas "[...]a começar pelo problema cognitivo da adequação da construção tradutora à realidade que se trata de conhecer" (p. 58). 
Para que o conhecimento, de fato, se efetive e esteja ao alcance de todos, o cérebro é, segundo Morin (1999), dotado de: dupla memória, uma hereditária e uma adquirida; terminais sensoriais extremamente sofisticados; e princípios/regras específicos que lhe permitem organizar o conhecimento em esquemas perceptivos a priori correspondentes à causalidade, necessidade e universalidade. Enfim, "A aptidão para aprender, propriamente dita, está ligada à plasticidade bioquímica do cérebro. Um conhecimento adquirido pode inscrever-se duravelmente sob a forma de uma propriedade associativa estável entre neurônios" (p. 69).

Vigotski, já no início do século 20, inaugura estudos que demonstram que há uma plasticidade muito grande do cérebro em sua reorganização para novas ligações neuronais, conforme os desafios e necessidades apresentadas à pessoa perante a vivência em sociedade. Também evidencia que a cultura passa a fazer parte da natureza humana. 0 processo geral do desenvolvimento humano segue duas linhas qualitativamente diferentes do desenvolvimento, os processos elementares de origem biológica e as funções superiores de origem sociocultural, e, por suposto, "[...] a história do comportamento da criança nasce do entrelaçamento dessas duas linhas" (VIGOTSKI, 2007, p. 42).

Como mencionado, as elaborações vigotskianas ultrapassam as explicações inatista e materialista do desenvolvimento e da aprendizagem. Vigotski contrapõe-se à ideia de que o desenvolvimento ocorre do individual para o social, e que o desenvolvimento biológico precede a aprendizagem. "Assim, para Vigotski, na melhor tradição de Marx e Engels, o mecanismo de mudança individual ao longo do desenvolvimento tem sua raiz na sociedade e na cultura" (COLE; SCRIBNER, 2007, p. XXVI).

Dessa ideia de que aprendizagem precede o desenvolvimento decorre a posição de que o ensino deve adiantar-se ao desenvolvimento, de que o bom ensino é o que conhece o nível do estudante para potencializar o desenvolvimento a partir dali. Ou seja, o bom ensino é aquele que utiliza uma metodologia que observa os estudantes em seu desenvolvimento como um todo, que percebe a atividade principal deles a partir das suas ações e interesses. Por isso, a compreensão da teoria de aprendizagem e desenvolvimento da psicologia histórico-cultural, pelos educadores, proporciona aos educandos, melhores oportunidades de se beneficiar do ensino escolar.

A escola deve se constituir em um ambiente de riquíssimas e diversificadas oportunidades de desenvolvimento, levando em consideração a interação entre adultos com mais qualificação e estudantes, utilizando os materiais da cultura e as práticas históricas humanas presentes neste local, destinados pela nossa sociedade para a socialização do conhecimento produzido.

Morin e Vigotski demonstram que o desenvolvimento humano sociocultural e histórico proporcionou um cérebro com potencialidades, com funções psicológicas superiores aptas à criação, indo, assim, além da simples adaptação à natureza. Esse fato representa a riqueza do ser humano e, muito além disso, o compromisso com as novas gerações, porque é possível compreender o desenvolvimento, a aprendizagem e a complexidade do conhecimento construído, para que se possa atualizar essas potencialidades a partir de processos de ensino que ofereçam o máximo de oportunidades a todos e todas. 
Promover um processo dialógico entre as reflexões do pensamento complexo e do desenvolvimento e aprendizagem a partir da teoria histórico-cultural, de maneira transdisciplinar, gera um humanismo complexo, que promove maneiras mais qualificadas de perceber o ensino e o papel da escola contemporânea no processo de desenvolvimento da pessoa humana, uma vez que, com a crescente complexificação da sociedade, coube à escola o papel de trabalhar o conhecimento, que deve ser percebido, pelos sujeitos, na totalidade e não em fragmentos, a partir do que a humanidade acumulou culturalmente no processo evolutivo.

Presentificando esse modo de perceber e agir na escola ante o conhecimento complexo, a aprendizagem e o desenvolvimento, na próxima seção a intenção é potencializar e demonstrar processos mais criativos de fazer educação transdisciplinar, em consonância com a dialógica e um humanismo que se pode denominar de complexo.

\section{POTENCIALIZANDO NARRATIVAS DE UMA EDUCAÇÃO MAIS CRIATIVA}

A complexidade do tempo presente e a necessidade de educar para uma vida meIhor, para todas as pessoas, implicam a inclusão das mesmas, no que respeita à possibilidade de conhecer o que a humanidade, durante sua história, construiu em forma de conhecimento. Argumenta-se que o pensamento de Morin tem a potência de nos desafiar à superação das dificuldades colocadas pelo próprio conhecimento, apresentadas anteriormente neste texto: a divisão sujeito e objeto do conhecimento; o conhecimento científico como verdade imutável e absoluta; a separação das condições de produção de conhecimento de seu resultado; e a supervalorização do computo em detrimento ao cogito.

Para esse propósito, o pensamento de Giorgio Agamben (2009) também contribui. Este nos alerta sobre a necessidade de estarmos ligados ao nosso tempo, que nos aprisiona, mas do qual devemos tomar distância, isto é, ele nos desafia a conhecer e enfrentar os problemas que nos impedem de sermos melhor enquanto humanidade. Já Michel Serres (2018), outro pensador contemporâneo que fala do nosso tempo, desafia-nos à criação de novas narrativas, porque precisamos de outros projetos e utopias, para irmos além do que temos, e uma nova narrativa para a organização do conhecimento, na escola, tem a ver com a percepção do conhecimento de forma transdisciplinar. ${ }^{10}$

A partir dessa concepção, propõe-se um diálogo com uma experiência de trabalho organizada na Rede Municipal de Ensino de Anchieta/SC, caracterizada como prática de ensino que considera o conceito da transdisciplinaridade. Em sua construção, inicialmente ela é planejada por todos os educadores desta rede e, em seguida, pelas escolas, que projetam as sequências didáticas específicas de acordo com suas realidades.

\footnotetext{
10"Entendemos, pois, a transdisciplinaridade como um princípio epistemológico que nos ajuda a superar as fronteiras disciplinares, as fronteiras do conhecimento, com base na atuação de um sujeito multidimensional, de um ser humano integral e integrado em sua dinâmica operacional reveladora de sua condição humana complexa. [...] uma metodologia transdisciplinar que trabalhe a complexidade da condição humana em seu processo de conhecer a realidade, integrando suas diferentes dimensões, ao dialogar com os diferentes níveis de materialidade do objeto transdisciplinar, na tentativa de transcendê-lo em busca de um conhecer mais global, integrado, profundo e pleno de significados" (MORAES, 2015, p. 88).
} 
Nessas escolas, desde o final dos anos 90, o trabalho é organizado a partir de projetos interdisciplinares, e no período de 2005 a 2008 a opção foi pelas redes temáticas, elaboradas a partir da escolha do tema geral, fruto de entrevistas realizadas com familiares de estudantes e lideranças das comunidades. Isso está de acordo com Hernández e Ventura (1998, p. 66), para os quais "[...] a perspectiva de globalização que se adota na escola, e que se reflete nos projetos de trabalho, trata de ensinar o aluno a aprender, a encontrar o nexo, a estrutura, o problema que vincula a informação e que permite aprender".

Junqueira Filho (2011), no livro Linguagens geradoras: seleção e articulação de conteúdos em educação infantil, mostra-se atento às múltiplas linguagens do universo infantil e propõe a organização dos projetos de trabalho na educação infantil. Embora este e os dois autores anteriores propõem a escolha da temática para estudo a partir das diversas linguagens das crianças ou dos seus interesses em determinados momentos, o que se diferencia na prática da referida cidade é que se leva em consideração apenas o universo e a percepção dos adultos para a escolha da temática a ser desenvolvida, com o envolvimento dos estudantes no trabalho realizado com eles na sala de aula, já com a temática escolhida.

Com um olhar para o conhecimento como totalidade, as equipes escolares participaram de formações que objetivam aprofundar as bases conceituais e conhecer experiências pedagógicas. Isso ocorre em duas universidades da região oeste catarinense: Universidade Comunitária da Região de Chapecó (Unochapecó) e Universidade do Oeste de Santa Catarina (Unoesc). Essa trajetória levou à organização dos conceitos a serem trabalhados para cada nível e área do conhecimento e, no ano de 2017, foi elaborado, a partir dos conceitos já elencados e da Base Nacional Comum Curricular, os direitos de aprendizagem e desenvolvimento dos estudantes da referida rede de ensino para cada grau e área.

A cada semestre é elaborado o projeto de trabalho pedagógico a ser desenvolvido nas escolas, com escolha da temática, objetivos, justificativa e pergunta exploratória, e são elencados os direitos de aprendizagem e conceitos a serem realizados dentro da temática. Nos momentos de planejamento dos projetos conta-se sempre com a assessoria de universidades por meio de professores e professoras que acompanham o trabalho e também com as experiências que o grupo vai acumulando em anos anteriores.

Como exemplo, no ano de 2017 uma escola do campo, que atende crianças da educação infantil, com idade entre três e seis anos incompletos, e uma classe multisseriada, com estudantes do 1 을 ao 3 을 anos do Ensino Fundamental, desenvolveu projeto pedagógico a partir do tema geral: "A arte de conviver: construindo valores para uma sociedade humanizada tendo a leitura como instrumento transformador". As professoras desenvolveram um dos objetivos elencados no projeto: "Encantar-se com o mundo e com suas transformações, bem como com as potencialidades humanas de interagir com o mundo e de produzir conhecimento e outros modos de vida mais humanizados (reconhecer-se como sujeito histórico)".

A partir desse objetivo, as professoras da Educação Infantil, do Ensino Fundamental e, especificamente, de Artes, realizaram atividades coletivas (com as duas turmas) e com cada turma em separado. Iniciaram o trabalho ouvindo um relato de experiência 
de uma antiga moradora da comunidade, que contou a vivência das pessoas que, a partir dos anos 60, passaram a morar no local e constituíram uma associação que organiza atividades econômicas coletivas que são instituídas pelas famílias em suas propriedades e visam o desenvolvimento da agricultura e o sustento familiar.

A partir desse relato de vivência comunitária, os estudantes do Ensino Fundamental fizeram suas anotações e a professora auxiliou para que, conforme os níveis de desenvolvimento da leitura e escrita, eles elaborassem seus registros para socializar com as famílias. Além disso, estudaram um texto histórico sobre os povos originários do Brasil, suas vivências e a relação com os estrangeiros que chegaram em nosso país, e realizaram atividades com problemas matemáticos relacionados aos períodos históricos para o estudo dos conceitos da adição e subtração.

Na sequência, esses estudantes desenvolveram atividades de interpretação de textos a partir da música Pindorama ${ }^{11}$ do grupo Palavra Cantada. Estudaram as características das vivências comunitárias e influências herdadas dos principais grupos étnicos que formaram o povo brasileiro. A professora de Artes, que é natural da capital baiana - Salvador - e descendente de escravos moçambicanos, em um dos momentos coletivos levou para as crianças verem, sentirem e experimentarem alimentos que utiliza em sua culinária, próprios da cultura moçambicana. Com base em duas receitas, as crianças produziram ainda, junto com as professoras, comidas que foram saboreadas no momento do lanche. Também foram promovidos estudos cartográficos das etnias que se estabeleceram e constituíram o povo brasileiro, e sobre as principais correntes migratórias dentro do país, que se deslocaram e se deslocam à procura de pão, terra e trabalho.

Enfim, essas e outras atividades foram desenvolvidas em conformidade com o nível de conhecimento de cada estudante e os direitos de aprendizagem e desenvolvimento de cada turma. No processo, constatou-se engajamento das crianças nos estudos, que passaram a perceber-se como sujeitos de história, olhando, assim, as suas vivências e dos outros como datadas e como objeto de observação das futuras gerações.

Uma análise sobre esses resultados demonstra que, enquanto permanecemos em nossas digressões sobre educar para a vida, a vida acontece e a educação também; nesse viver e educar muitas experiências de transdisciplinaridade, que dimensionam o

\footnotetext{
${ }^{11}$ (Terra à vista!)

Pindorama, Pindorama

É o Brasil antes de Cabral

Pindorama, Pindorama

É tão longe de Portugal

Fica além, muito além

Do encontro do mar com o céu

Fica além, muito além

Dos domínios de Dom Manuel

Vera Cruz, Vera Cruz

Quem achou foi Portugal

Vera Cruz, Vera Cruz

Atrás do Monte Pascoal

Bem ali Cabral viu

Dia 22 de abril

Não só viu, descobriu

Toda a terra do Brasil

Pindorama, Pindorama.
} 
conhecimento como totalidade, são realizadas, mostrando que o conhecimento que se faz presente de fato na vida das pessoas também está presente nas instituições de ensino. Assim como a experiência relatada, Moraes (2015) também apresenta experiências significativas no ensino e que merecem ser visitadas pelos educadores que se comprometem com o conhecimento.

A mesma autora trabalha em um estudo que resultou no livro Transdisciplinaridade, criatividade e educação: fundamentos ontológicos e epistemológicos, no qual aborda a necessidade de associar a pluralidade disciplinar à complexidade humana. Nos termos dela, "[...] necessitamos de uma educação integral transdisciplinar nutrida por novas visões conceituais capazes de promoverem um pensamento que não mais fragmente, reduza ou dissocie a realidade" (MORAES, 2015, p. 20).

Neste mesmo livro, a autora demonstra, também, que essa possibilidade de novas propostas educativas relacionadas à complexidade do conhecimento, à criatividade e a potencialidades humanas, não prescinde da docência, a qual necessita de "[...] uma formação baseada na interdependência complexa entre o sujeito cognoscente e os diversos saberes teóricos, práticos e existenciais" (MORAES, 2015, p. 23). Afinal, trabalhar de forma transdisciplinar "[...] significa ir mais além do que foi dado e herdado de antemão, acercar-se do mistério humano, transgredir fronteiras do conhecimento oficial e atrever-se a aventurar-se, a explorar novos territórios" (MORAES, 2015, p. 126).

A partir disso, pode-se afirmar que a metodologia de trabalho a ser realizada em escolas será baseada em projetos de aprendizagem e desenvolvimento comunitário com o intuito de exercitar e desenvolver variadas capacidades dos sujeitos do processo. Ademais, "[...] devemos defender plenamente que a escola criativa e transdisciplinar do futuro seja necessariamente ética em todos os seus elementos funcionais, materiais e pessoais" (MORAES, 2015, p. 135).

Pretende-se, ainda, conforme a autora, que em todo processo educativo sejam trabalhadas quatro dimensões fundamentais: o aprender a ser, com autoconhecimento e construção de sentidos; o aprender a conviver, a cidadania e a democracia, quando a escola precisa constituir-se em uma comunidade democrática de aprendizagem; a dimensão do aprender a aprender; e, por fim, o aprender a comprometer-se, desenvolvendo a sensibilidade e a solidariedade.

Morin (2000), por sua vez, argumenta no livro Os sete saberes necessários à educação do futuro acerca da importância de discutir nas escolas, espaço em que se trabalha o conhecimento, os equívocos do próprio conhecimento e, por outro lado, o conhecimento pertinente: ensinar aos estudantes a condição humana, complexa, única e relacionada; ensinar a nossa identidade terrena, profundamente relacionada a todos os outros que vivem conosco na Terra; ensinar que as incertezas são maiores que os determinismos e que as verdades absolutas não existem; educar para a compreensão; e, finalmente, ensinar a ética do gênero humano para que cada um perceba-se indivíduo, parte da sociedade e parte da espécie.

Morin (2015) aposta também no desejo de conhecer, presente nas crianças e jovens: 
Nas crianças e jovens existe uma fantástica curiosidade por todas as coisas, com frequência desapontada por um ensino que divide a realidade do mundo em compartimentos separados, [...] essa curiosidade pode ser reanimada e transformada em desejo de saber, não apenas com e por meio de um professor possuído por Eros, mas também por uma formação enriquecida de temáticas apaixonantes como a dos sete saberes e a da educação para a civilização (p. 180-181).

Daí a importância de fortalecer e avançar, cada vez mais, de forma corajosa e autêntica, nos processos formativos já existentes, como na experiência aqui problematizada e refletida.

\section{CONSIDERAÇÕES FINAIS}

As experiências bonitas, que olham para as potencialidades dos estudantes e para a complexidade do conhecimento, estão presentes em muitos lugares onde novas narrativas estão sendo gestadas e existem pessoas comprometidas, que pensam uma educação em que o ensinar seja possível a todos e todas. Basta que tenhamos a sensibilidade para reconhecer, visibilizar e abrir espaços para que estas experiências sejam potencializadas. Neste texto foram apresentados alguns elementos de uma dessas experiências: a da Rede Municipal de Anchieta/SC.

Trata-se de uma experiência eivada de escolhas que se dão em determinadas condições. Em As cidades invisíveis, Calvino (1990), a partir das narrativas de Marco Polo ao grande Kublai Khan sobre as cidades que visitou em suas missões diplomáticas pelo império mongol, propõe discernimento para escolher no "inferno dos vivos" (caso ele exista):

O inferno dos vivos não é algo que será; se existe, é aquele que já está aqui, o inferno no qual vivemos todos os dias, que formamos estando juntos. Existem duas maneiras de não sofrer. A primeira é fácil para a maioria das pessoas: aceitar o inferno e tornar-se parte deste até o ponto de deixar de percebê-lo. A segunda é arriscada e exige atenção e aprendizagem contínuas: tentar saber reconhecer quem e o que, no meio do inferno, não é inferno, e preservá-lo, e abrir espaço (p. 150).

O propósito de uma escola criativa, que observa a aprendizagem e o desenvolvimento do estudante, ao mesmo tempo em que valoriza o conhecimento que foi construído pelas pessoas no decorrer da história das civilizações, e que trabalhe o conhecimento de forma transdisciplinar e as pessoas nas suas múltiplas dimensões, começa a existir quando se acredita que ela é possível e à medida que se possibilita acontecimentos que operem na construção do conhecimento complexo.

Olhando para a teoria do desenvolvimento humano proposta por Vigotski, para o conceito da complexidade do conhecimento, demonstrada por Morin, e para o profundo compromisso que devemos ter com as novas gerações, permite-se afirmar que refletir sobre o conhecimento a ser trabalhado na escola, escolher o caminho, pautado no que é fundamental do que já foi construído para ensinar a viver hoje, observar o desenvolvimento do estudante, para que seja realizado um bom ensino que promova as potencialidades de cada um, estão entre as tarefas que demonstram a natureza complexa, desafiadora e apaixonante de educar na contemporaneidade. 


\section{REFERÊNCIAS}

AGAMBEN, Giorgio. O que é o contemporâneo? E outros ensaios. Trad. Vinícius Nicastro Honesko. Chapecó: Argos, 2009.

ARENDT, Hannah. Entre o passado e o futuro. São Paulo: Perspectiva, 2002.

BRASIL. Lei no 13.415 de 16 de fevereiro de 2017. Diário Oficial da União. 17 fev. 2017.

CALVINO, Ítalo. As cidades invisíveis. Trad. Diogo Mainardi. São Paulo: Companhia das Letras, 1990.

COLE, Michael; SCRIBNER, Sylvia. Introdução. In: VIGOTSKI, Lev Seminovich. A formação social da mente. 7. ed. Trad. José Cipolla Neto, Luís Silveira Menna Barreto e Solange Castro Afeche. São Paulo: Martins Fontes, 2007. p. XVII a XXXVI.

DESCARTES, René. Discurso do método. Trad. Paulo Neves. Porto Alegre: LP\&M Editores, 2005.

HERNÁNDEZ, Fernando; VENTURA, Montserrat. A organização do currículo por projetos de trabalho. 5. ed. Porto Alegre: Artmed, 1998.

IBGE. Instituto Brasileiro de Geografia e Estatística. 2012.

JUNQUEIRA FILHO, Gabriel de Andrade. Linguagens geradoras: seleção e articulação de conteúdos em educação infantil. 5. ed. Porto Alegre: Mediação, 2011.

MORAES, Maria Cândida. Transdisciplinaridade, criatividade e educação: fundamentos ontológicos e epistemológicos. Colaboração Juan Batalloso Navas. Campinas: Papirus, 2015.

MORIN, Edgar. O método 3: o conhecimento do conhecimento. Trad. Juremir Machado da Silva. 2. ed. Porto Alegre: Sulina, 1999.

MORIN, Edgar. Os sete saberes necessários à educação do futuro. Trad. Catarina Eleonora F. da Silva, Jeanne Sawaya. 2. ed. São Paulo: Cortez; Brasília, DF: Unesco, 2000.

MORIN, Edgar. Ciência com consciência. Trad. Maria D. Alexandre e Maria Alice Sampaio Dória. 14. ed. Rio de Janeiro: Bertrand Brasil, 2010.

MORIN, Edgar. Ensinar a viver: manifesto para mudar a educação. Trad. Edgard de Assis Carvalho, Mariza Perassi Bosco. Porto Alegre: Sulina, 2015.

O MUNICÍPIO de Anchieta... Disponível em:http://www.anchieta.sc.gov.br/cms/pagina/ver/codMapaltem/56653. Acesso em: 24 mar. 2018.

O “NOVO Ensino Médio". Disponível em: http//portal.mec.gov.br/component/content/article?id=40361\#nem_01. Acesso em: 20 mar. 2018.

PERES, Sandra; TATIT, Paulo. Pindorama. Álbum Canções Curiosas. São Paulo: Palavra Cantada, 1998

PRESIDENTE DA REPÚBLICA. Medida Provisória (MP) no 746/16 - Reformulação do Ensino Médio. Brasília: Diário Oficial da União, 23 set. 2016.

SERRES, Michel. "Não só progresso. É preciso outra utopia”. Entrevista com Michel Serres. Disponível em: http://www.ihu.unisinos.br/78-noticias/568444-nao-so-progresso-e-preciso-outra-utopia-entrevista-com-michel-serres. Acesso em: 24 mar. 2018.

VIGOTSKI, Lev Seminovich. A formação social da mente. 7. ed. Trad. José Cipolla Neto, Luís Silveira Menna Barreto e Solange Castro Afeche. São Paulo: Martins Fontes, 2007. 